\title{
ANALISIS NILAI TAMBAH OLAHAN SALE SALAK LOKAL TASIKMALAYA DI KELOMPOK WANITA TANI (KWT) MELATI KELURAHAN CIAKAR KECAMATAN CIBEUREUM KOTA TASIKMALAYA
}

\author{
ANALYSIS OF THE ADDITIONAL VALUE OF SALES PROCESSING \\ SALAK LOCAL TASIKMALAYA \\ IN KELOMPOK WANITA TANI (KWT) MELATI KELURAHAN CIAKAR KECAMATAN \\ CIBEUREUM KOTA TASIKMALAYA
}

TIEN SUGIHARTINI, NENI KARTINI, RINA NURYATI

Program Studi Agribisnis, Program Pascasarjana Universitas Siliwangi

Email: ugihtien@gmail.com, kartinineni34@gmail.com, rinanuryati@unsil.ac.id

\begin{abstract}
ABSTRAK
Memasuki dunia industri yang semakin berkembang pada saat ini membuat persaingan antar pelaku bisnis semakin kuat. adanya persaingan memaksa pemilik bisnis untuk mencari solusi terkait dengan strategi yang baik bagi usaha yang dikelolanya,Tujuan penelitian adalah untuk 1).Menganalisis Pendapatan dari usaha pengolahan buah salak lokal Tasikmalaya menjadi sale salak 2). Menganalisis efisiensi dari usaha pengolahan buah salak lokal Tasikmalaya menjadi sale salak 3) Menganalisis nilai Tambah dari usaha pengolahan Buah salak Lokal Tasikmalaya menjadi sale salak. Penelitian di laksanakan di Keompok Wanita Tani (KWT) Melati di Kelurahan Ciakar Kecamatan Cibeureum Kota Tasikmalaya.Hasil penelitian menunjukkan bahwa 1) total Pendapatan bersih olahan sale salak sebesar $\mathrm{Rp}$ 456.500/ satu kali proses produksi2) Nilai Efiseien perhitungan ratio $\mathrm{R} / \mathrm{C}$ dari olahan sale salak sebesar 1,30 \% 3) nilai tambah yang diperoleh dari olahan sale salak sebesar Rp.3.250/Kg, yang berarti usaha olahan sale salak di KWT Melati Kelurahan Ciakar Kecamatan Cibeureum Kota Tasimalaya dapat meningkatkan pendapatan dan nilai tambah.
\end{abstract}

Kata kunci: Keunggulan, Efisien, Nilai Tambah, Sale salak.

\section{ABSTRACT}

Entering the increasingly developing world of industry today, competition between business actors is getting stronger. The existence of competition forces business owners to find solutions related to a good strategy for the business they manage. The research objectives are to 1) Analyze the advantages of the local Tasikmalaya salak fruit processing business to become salak salak 2). Analyze the efficiency of the local Tasikmalaya salak fruit processing business into salak salak 3) Analyze value Addition of the local Tasikmalaya salak fruit processing business to salak salak. The research was carried out in the Melati Women Farmers Group (KWT) in Ciakar Village, Cibeureum District, Tasikmalaya City. The results showed that 1) the total net profit of the salak sale process was Rp 456,500 / one production process 2) The efficiency value of the calculation of the $R$ / $C$ ratio of the salak sale process was $1.30 \%$ 3) the added value obtained from the salak sale process was Rp. .3.250 / $\mathrm{Kg}$, which means that the business of selling salak in KWT Melati, Ciakar Village, Cibeureum District, Tasimalaya City can increase income and added value.

Keywords: Excellence, Efficient, Value Added, Salak Sale.

\section{PENDAHULUAN}

Kota Tasikmalaya merupakan suatu wilayah dengan potensi lahan pertanian sebesar 70,92 \% ( Statistik dinas

Ketahanan Pengan, Pertanian dan Perikanan Tahun 2019). Kelurahan Ciakar merupakan salah satu kelurahan yang ada 
di Kota Tasikmalaya, Kelurahan tersebut cukup strategis dalam pengembangan komoditas hortikultura, khususnya komoditi salak, karena memiliki potensi iklim yang baik dan cocok untuk pembudidayaan buah salak (Salacca Edulis) .

Salak lokal Tasikmalaya yang lebih dikenal dengan nama salak Manonjaya, Jenis salak ini ada dua macam berdasarkan ukurannya: kecil dan besar. Jenis salak yang kecil berkulit tipis dan bersisik lembut. Daging buahnya agak tipis, berwarna putih keruh, tidak masir, dan teksturnya renyah. Rasanya manis segar dan ada sedikit rasa sepat.

Jenis salak yang besar kulit buahnya tebal, bahkan paling tebal di antara jenis-jenis salak manonjaya lainnya. Sisiknya juga besar-besar. Daging buahnya tebal dan berwarna putih kekuningan. Teksturnya seperti jenis salak yang kecil, renyah dan tidak masir. Rasanya tidak begitu manis, rasa sepetnya yang lebih dominan. Jenis salak ini jarang ditanam petani, Salah satu kelemahan yang dimiliki oleh salak Manonjaya adalah rasanya yang tidak semanis dengan salak yang umumnya beredar di pasaran saat ini seperti salak pondoh. Untuk itu, salah satu upaya yang perlu dilakukan untuk meningkatkan konsumsi masyarakat terhadap salak
Manonjaya adalah inovasi menjadi produk olahan.

kandungan gizi yang terkandung dalam buah salak terdapat dalam Tabel di bawah ini

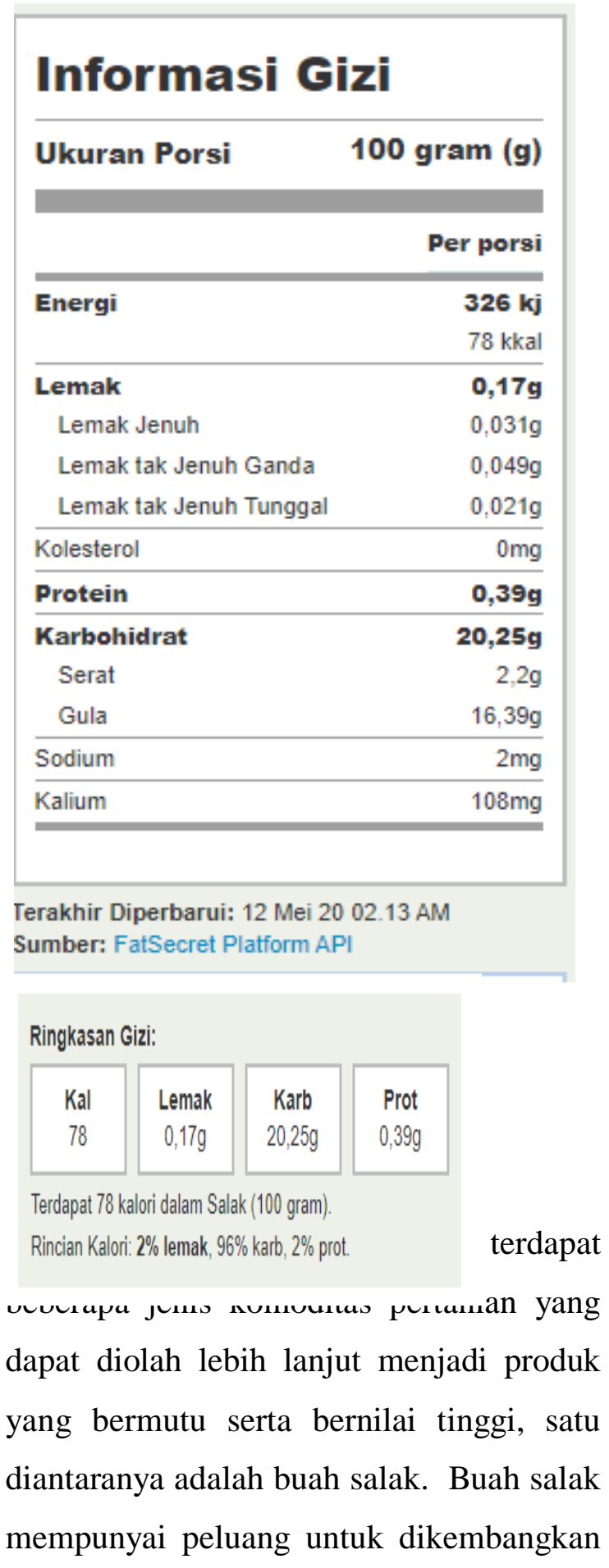


karena potensinya yang baik untuk kegiatan agribisnis dan agroindustri. Buah Salak tergolong komoditas yang bersifat musiman dan mudah rusak sehingga memberikan kerugian bagi para petani, hal ini dinyatakan oleh Hapsari, dkk (2008). Buah salak hanya bisa bertahan setelah dipetik kurang lebih 6-7 hari. Upaya untuk menghadapi masalah umur simpan salak yang relatif pendek tersebut adalah dengan melakukan pengolahan hasil pertanian

Industri pengolahan hasil pertanian merupakan subsistem yang sangat penting dikembangkan untuk mendukung pembagunan pertanian. Dikembangkannya industri ini dapat memberikan nilai tambah dari produk pertanian dan membuka kesempatan kerja serta menyediakan produk makanan yang beragam (Herliska, 2017). Dengan demikian, subsistem agroindustri mempunyai prospek yang baik di masa mendatang dan dapat diandalkan untuk memajukan perekonomian Indonesia.

Nilai tambah (value added) adalah pertambahan nilai suatu komoditas karena melalui proses pengolahan, pengangkutan maupun penyimpanan dalam suatu produksi. Dalam proses pengolahan, nilai tambah dapat diartikan sebagai selisih antara nilai produk dengan nilai biaya bahan baku dan bahan input lainnya.
Untuk mengetahui besar nilai tambah yang diberikan Sale Salak pada salak sebagai bahan baku maka diperlukan analisis nilai tambah sehingga bisa diketahui apakah usaha yang dijalankan tersebut efisien dan memberikan pendapatan.

KWT Melati merupakan Kelompok Wanita Tani yang berada di Kelurahan Ciakar yang bergerak dibidang industri pengolahan salak lokal .Industri ini mengolah buah salak lokal Tasikmalaya menjadi sale salak, Tujuan penelitian adalah untuk 1). Menganalisis Pendapatan dari usaha pengolahan buah salak lokal Tasikmalaya menjadi sale salak 2). Menganalisis efisiensi dari usaha pengolahan buah salak lokal Tasikmalaya menjadi sale salak 3) Menganalisis nilai Tambah dari usaha pengolahan buah salak Lokal Tasikmalaya menjadi sale salak di KWT Melati .

\section{METODE PENELITIAN}

Metode penelitian yang digunakan dalam penelitian ini adalah studi kasus. Studi kasus menurut Sugiyono (2016) adalah dimana peneliti melakukan eksplorasi secara mendalam terhadap program, kejadian, proses, aktivitas terhadap satu oran atau lebih.

\section{Tempat dan Waktu Penelitian}


Penelitian ini dilaksanakan di KWT Melati yang berlokasi di Kelurahan Ciakar Kecamatan CibeureumKota Tasikmalaya, Penelitian dilaksanakan pada Bulan Desember 2020.

\section{Metode Pengumpulan Data}

Pengumpulan data meliputi data primer dan data sekunder. Data primer diperoleh melalui wawancara langsung pada Ketua KWT Melati dan Anggota (tenaga kerja) serta observasi langsung , Data sekunder diperoleh dari berbagai literatur yang berhubungan dengan penelitian ini.

\section{Metode Analisis Data}

\section{Analisis Pendapatan usaha olahan Sale salak}

Analisis yang digunakan dalam penelitian ini adalah analisis pendapatan yaitu untuk melihat berapa pendapatan dari industri ini dengan menggunakan rumus :

$\pi=\mathbf{T R}-\mathbf{T C}$

Dimana $: \mathrm{TR}=\mathrm{Y}$ x Py

$$
\mathrm{TC}=\mathrm{FC}+\mathrm{VC}
$$

Ket.

$$
\begin{array}{ll}
\pi & =\text { Pendapatan usaha }(R p) \\
T R & =\text { Total Penerimaan }(R p) \\
T C & =\text { Total Biaya }(R p) \\
Y & =\text { Produksi }(k g) \\
P y & =\text { Harga Produk }(R p) \\
F C & =\text { Biaya Tetap }(R p) \\
V C & =\text { Biaya Variabel }(R p)
\end{array}
$$

\section{Analisis Efisiensi}

Efisiensi usaha pengolahan buah salak lokal menjadi sale salak dilakukan dengan menggunakan analisis perhitungan $\mathrm{R} / \mathrm{C}$ Ratio, yaitu dengan membandingkan antara penerimaan dengan total biaya.

Kriteria Keputusan:

$\mathrm{R} / \mathrm{C}>1$ Usaha untung

$\mathrm{R} / \mathrm{C}<1$ Usaha rugi

$\mathrm{R} / \mathrm{C}=1$ Usaha Impas

\section{Analisis Nilai Tambah}

\begin{tabular}{|c|c|}
\hline Variabel & Notasi \\
\hline \multicolumn{2}{|l|}{ Output, Input dan Harga } \\
\hline Output (kg/bulan) & $\mathrm{A}$ \\
\hline Bahan baku ( $\mathrm{kg} /$ bulan) & B \\
\hline Tenaga kerja (HOK/bulan) & $\mathrm{C}$ \\
\hline Faktor konversi & $\mathrm{D}=\mathrm{A} / \mathrm{B}$ \\
\hline Koefisien tenaga kerja $(\mathrm{HOK} / \mathrm{kg})$ & $\mathrm{E}=\mathrm{C} / \mathrm{B}$ \\
\hline Harga output (Rp/kg) & $\mathrm{F}$ \\
\hline $\begin{array}{l}\text { Upah rata-rata tenaga kerja } \\
\text { (Rp/HOK) }\end{array}$ & G \\
\hline \multicolumn{2}{|l|}{ Pendapatan dan nilai tambah } \\
\hline Harga bahan baku ( $\mathrm{Rp} / \mathrm{kg})$ & $\mathrm{H}$ \\
\hline Sumbangan input lain ( $\mathrm{Rp} / \mathrm{kg}$ ) & I \\
\hline Nilai output $(\mathrm{Rp} / \mathrm{kg})$ & $\mathrm{J}=\mathrm{D} \times \mathrm{F}$ \\
\hline Nilai tambah (Rp/kg) & $\mathrm{K}=\mathbf{J}-\mathrm{I}-\mathrm{H}$ \\
\hline Rasio nilai tambah ( persen) & $\mathrm{L}=(\mathrm{K} / \mathrm{J}) \times 100$ \\
\hline Imbalan tenaga keria $(\mathrm{Rp} / \mathrm{kg})$ & persen \\
\hline Bagian tenaga keria (persen) & $\mathrm{M}=\mathrm{E} \times \mathrm{G}$ \\
\hline Keuntungan $(\mathrm{Rp} / \mathrm{kg})$ & $\mathrm{N}=(\mathrm{M} / \mathrm{K}) \times 100$ \\
\hline \multirow[t]{3}{*}{ Bagian keuntungan ( persen) } & persen \\
\hline & $\mathrm{O}=\mathrm{K}-\mathrm{M}$ \\
\hline & $\mathrm{P}=\underset{\text { persen }}{(\mathrm{O} / \mathrm{K}) \times 100}$ \\
\hline \multicolumn{2}{|l|}{ Balas Jasa untuk Faktor Produksi } \\
\hline Margin keuntungan $(\mathrm{Rp} / \mathrm{kg})$ & $\mathrm{Q}=\mathbf{J}-\mathrm{H}$ \\
\hline Keuntungan ( persen) & $\mathrm{R}=\mathrm{O} / \mathrm{Q} \times 100$ \\
\hline Tenaga kerja ( persen) & persen \\
\hline \multirow{4}{*}{ Input lain ( persen) } & $S=M / Q \times 100$ \\
\hline & persen \\
\hline & $T=I / Q \times 100$ \\
\hline & persen \\
\hline
\end{tabular}

untuk menghitung besarnya pertambahan nilai dari Sale salak, digunakan tabulasi metode Hayami (1987) dalam Hakim L, Rochdiani D, Noormansyah Z (2016)

Tabel 2. Prosedur perhitungan metode nilai tambah Hayami 


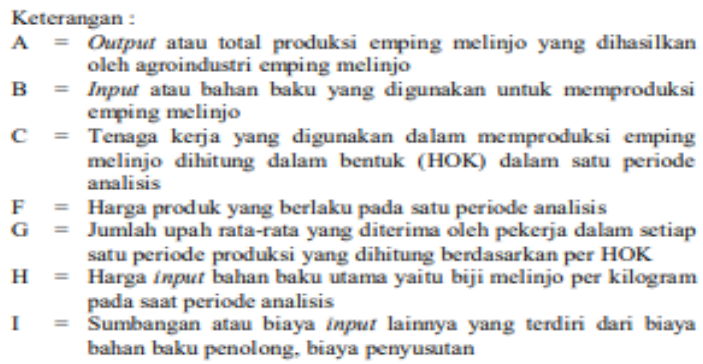

\section{HASIL DAN PEMBAHASAN}

\section{Pendapatan pengolahan buah}

salak lokal Tasikmalaya menjadi sale salak

Biaya dalam proses produksi Sale Salak terdiri dari biaya bahan baku utama, bahan baku penolong dan biaya tenaga kerja. Secara rinci biaya produksi untuk satu kali proses produksi diberikan pada Tabel 1

Tabel 1. Biaya Produksi Olahan Sale Salak dalam Satu Kali Proses Produksi Di KWT Melati Kelurahan Ciakar Kota Tasikmalaya Tahun 2020

\begin{tabular}{|c|c|c|c|c|c|}
\hline No & Bahan Baku & Volume & Satuan & Harga $(\mathrm{Rp})$ & Jumlah (Rp) \\
\hline \multirow[t]{4}{*}{ I } & Bahan Baku & & & & \\
\hline & Salak & 100 & $\mathrm{Kg}$ & 3.500 & 350.000 \\
\hline & Gula Pasir & 5 & $\mathrm{Kg}$ & 13.500 & 67.500 \\
\hline & Jumlah & & & & 417.500 \\
\hline \multirow[t]{6}{*}{ II } & Bahan Baku Penolong & & & & \\
\hline & $\operatorname{Air}(1,5 \mathrm{~L})$ & 2 & buah & 5.000 & 10.000 \\
\hline & Gas $3 \mathrm{KG}$ & 1 & buah & 24.000 & 24.000 \\
\hline & Plastik Kemasan & 90 & buah & 1.300 & 117.000 \\
\hline & Puring Nasi & 10 & buah & 3.000 & 30,000 \\
\hline & Jumlah & & & & 181.000 \\
\hline \multirow[t]{3}{*}{ III } & Biaya Tenaga Kerja & & & & \\
\hline & Tenaga Kerja Harian ( 2 Hari) & 4 & orang & 30,000 & 240.000 \\
\hline & Jumlah Biaya & & & & 838.500 \\
\hline
\end{tabular}

Bahan baku utama dalam produksi sale salak terdiri dari buah salak lokal Tasikmalaya dan gula pasir. Rata-rata biaya untuk satu kali proses produksi adalah sebesar Rp 417.500. Bahan baku penolong terdiri dari air, plastik kemasan gas, dan puring dengan total biaya yang dikeluarkan untuk satu kali proses produksi sebesar Rp 181.000. KWT Melati saat ini memiliki 8 orang Anggota dengan tenaga kerja sebanyak 4 orang (dari Anggota). Dalam satu kali proses produksi biaya untuk tenaga kerja adalah Rp. 240.000.

Analisis pendapatan dalam penelitian ini digunakan untuk mengetahui besarnya yang diperoleh dari usaha sale salak di Kelurahan Ciakar Kecamatan Cibeureum Kota Tasikmalaya dalam satu kali produksi dengan cara menghitung selisih antara jumlah total penerimaan dan total biaya yang dikeluarkan terlihat pada Tabel 2.

Tabel 2. Rincian Penerimaan, Biaya Produksi dan PendapatanUsaha Sale Salak

\begin{tabular}{|c|c|c|}
\hline No. & Uraian & Harga $(R \mathrm{P})$ \\
\hline | & Penerimaan (TR) & \\
\hline & Produks (Kg) 13,5 Kg X150,000 & $2,025,000$ \\
\hline$\|$ & Biaya Produksi (TC) & \\
\hline & a. Biaya Penyusutan & 730,000 \\
\hline & b. Biaya bahan baku & 417,500 \\
\hline & C. Biaya bahan penolong & 181,000 \\
\hline & d. Biaya tenaga kerja & 240,000 \\
\hline & Total & 1.568 .500 \\
\hline & Keuntungan (TR-TC) & 456.500 \\
\hline
\end{tabular}

\section{Efisiensi Pengolahan Sale Salak}

Efisiensi usaha pengolahan buah salak menjadi sale salak dilakukan dengan 
menggunakan analisis perhitungan $\mathrm{R} / \mathrm{C}$ Ratio, yaitu dengan membandingkan antara penerimaan dengan total biaya.

Tabel 3. Efisiensi Usaha Sale Salak di KWT Melati dalam satu kali produksi

\begin{tabular}{|r|r|r|}
\hline No & Uralan & \multicolumn{1}{|c|}{ Jumlah } \\
\hline 1 & Penerimaan $(\mathrm{R})$ & $2,025,000$ \\
\hline 2 Total Biaya $(\mathrm{C})$ & $1,568,500$ \\
\hline & Efisiensi $(\mathrm{R} / \mathrm{C})$ & 1,3 \\
\hline
\end{tabular}

\section{Nilai Tambah dari usaha pengolahan buah salak lokal Tasikmalaya menjadi sale salak .}

Analisis nilai tambah pengolahan sale salak dalam satu kali proses produksi di KWT Melati disajikan pada Tabel 4.

\begin{tabular}{|c|c|c|}
\hline No & Hasil Produksi, Bahan Baku dan Harga & \\
\hline 1 & Hasil produksi (Kg/proses produksi ) & 13,5 \\
\hline & Bahan baku (Kg/proses produksi) & 100 \\
\hline 3 & Input tenaga kerja ( HOK/proses produksi ) & 2 \\
\hline 4 & Falktor Konversi ( $\mathrm{Kg}$ output $/ \mathrm{Kg}$ bahan baku) & 0,14 \\
\hline 5 & Koefisien Tenaga Kerja ( HOK/Kg bahan baku) & 0,02 \\
\hline 6 & Harga Produksi (Rp/Kg) & 150.000 \\
\hline & Upah Rata-rata tenaga kerja (Rpproses produksi) & 30.000 \\
\hline & Pendapatan dan Nilai Tambah & \\
\hline 8 & Harga Bahan Baku ( Rp $/ \mathrm{kg}$ ) & 3.500 \\
\hline 9 & Sumbangan bahan lain Rp/Kg bahan baku) & 13.500 \\
\hline 10 & Nilai Produk & 20.250 \\
\hline & a. Nilai tambah $(\mathrm{Rp} / \mathrm{Kg})$ & 3.250 \\
\hline & b. Ratio nolai Tambah (\%) & 16 \\
\hline & c. Imbalan tenaga kerja $(\mathrm{Rp} / \mathrm{Kg})$ & 600 \\
\hline & d. Baguian Tenaga Kerja & 18,46 \\
\hline & e. Keuntungan $(\mathrm{Rp} / \mathrm{Kg})$ & 2.650 \\
\hline & f. Bagian Keuntungan & 81,54 \\
\hline 11 & Balas jasa untuk falkir prduksi margin $(\mathrm{Rp} / \mathrm{Kg})$ & 16.750 \\
\hline & a. Keuntungan (\%) & 15,82 \\
\hline & b. Tenaga Kerja (\%) & 3,58 \\
\hline & c. Input Lain (\%) & 80,60 \\
\hline
\end{tabular}

Nilai produk merupakan hasil perkalian antara faktor konversi dengan harga produk. Nilai produk sale salak yang dihasilkan KWT Melati sebesar Rp 20.250/Kg. Imbalan tenaga kerja merupakan besarnya imbalan yang diperoleh tenaga kerja dalam mengolah bahan baku salak. Nilai imbalan tenaga kerja pada sebesar Rp 600 per kilogram. Besarnya pendapatan yang didapatkan oleh agroindustri Sale salak di KWT Melati Kelurahan Ciakar Kecamatan Cibeureum Kota Tasikmalaya sebesar Rp 2.650/Kg Hal tersebut dikarenakan terdapat pengaruh dari nilai tambah dan imbalan tenaga kerja. Pendapatan ini merupakan nilai tambah bersih serta merupakan imbalan bagi agroindustri. Nilai tambah agroindustri Sale salak di KWT Melati sebesar $\mathrm{Rp}$ 3.250.Hasil perhitungan tersebut disimpulkan bahwa usaha pengolahan sale salak di Kelurahan Ciakar Kecamatan CibeureumKota Tasikmalaya layak untuk dikembangkan kedepannya.

Tabel 4 menunjukkan bahwa hasil produksi sale salak rata-rata per satu kali proses produksi sebanyak 13,5 kilogram. Nilai konversi pada olahan sale salak di KWT Melati Kelurahan Ciakar Kecamatan Cibeureum Kota Tasikmalaya sebesar 0,14 , berarti bahwa setiap satu kilogram buah salak yang diolah menghasilkan sale 
salak sebesar 0,14 kilogram. Nilai konversi yang dihasilkan olahan sale salak di KWT Melati bernilai kecil dikarenakan pengolahan masih menggunakan peralatan yang sederhana dalam proses produksinya. Peralatan yang digunakan untuk proses produksi antara lain, pisau, wajan, ember, tampah, susuk, talenan dan kompor.

\section{KESIMPULAN DAN SARAN}

\section{Kesimpulan}

Berdasarkan hasil penelitian yang telah dilakukan pada usaha pengolahan sale salak di Kelurahan CiakarKecamatan CibeureumKota Tasikmalaya dapat diperoleh kesimpulan sebagai berikut :

1. Pengolahan sale salak memberikan Pendapatan yang diterima adalah sebesar Rp.456.500dalam satu kali proses produksi.

2. Efisiensi usaha pengolahan buah salak lokal Tasikmalaya menjadi sale salak di Kelurahan CiakarKecamatan Cibeureum, Kota Tasikmalaya, adalah sebesar 1,30. Hal ini berarti bahwa pengolahan sale salak di kelurahan Ciakar Kecamatan Cibeureum Kota Tasikmalayamenunjukkan sudah efisien.

3. Pengolahan buah salak lokal menjadi sale salak pada KWT Melati memberikan Nilai tambah sebesar
Rp.3.250/Kg dengan marjin pendapatan sebesar $15,82 \%$.

\section{Saran}

Usaha industri olahan sale salak dalam memproduksi sale salak tidak hanya dengan cita rasa satu jenis, tetapi bisa mengunakan berbagai cita rasa dengan tujuan agar dapat meninggatkan selera konsumen.

\section{DAFTAR PUSTAKA}

Andra, 27 Oct Artikel Value Added / Nilai Tambah Adalah : Pengertian dan Manfaat. https://comflit.com/valueadded

Desy Rozalia, 130210301014; 2019, Strategi Diversifikasi Produk Olahan Buah Salak Pada Industri Winna Sari Desa Pronojiwo Kabupaten Lumajang"

Hakim L, Rocdiani D, Noormansyah Z. 2016. Analisis Nilai Tambah Agroindustri Opak Ketan di Desa Sukahurip Kecamatan Pamarican Kabupaten Ciamis. Jurnal Agroinfo Galuh Vol 3 Nomor 1, September 2016. ISSN 2356-4903. Fakultas Pertanian Universitas Galuh. Ciamis.

Herliska, A. Y. R. 2017. Analisis Pendapatan Dan Nilai Tambah Produk Olahan Berbahan Baku Salak Pada Skala Industri Rumah Tangga Di Kabupaten Sleman. Yogyakarta. Research Repository of UMY Repository is a digital collection of open access research publications from Universitas Muhammadiyah Yogyakarta 
Hidakitha 27 November 2012. Salak Manonjaya. This Wordpress.Com site is the bee's knees

Hapsari H., Djuwendah E., Karyani T., 2008. Peningkatan Nilai Tambah dan Strategi Pengembangan Usaha Pengolahan Salak Manonjaya. Universitas Padjadjaran. Jurnal Agrikultura, Volume 19, Nomor 3 Tahun 2008 ISSN 08532885.Halaman 208-215.

Juliana Raranta Eyverson Ruauw Nordy Fritsgerald Lucky Waney 2018. Analisis Nilai Tambah Buah Salak Sebagai Bahan Baku Dodol Salak Pada Ud Mandiri Di Desa Pangu I Kecamatan Ratahan Kabupaten Minahasa Tenggara Jurnal AgriSosio Ekonomi Unsrat, Volume 14 Nomor 3, September 2018 : 279 286, ISSN 1907-4298,

Ni Kade Widiani 1 Max Nur Alam, dan Abdul Muis 2 1. 2019. Analisis Nilai Tambah Olahan Dodol Salak di Desa Tamarenja Kabupaten Donggala . Mitra Sains, Volume 7 Nomor 3, September 2019 hlm 287-297 ISSN 2302-2027
Sumeru Ashari , April 2013, Buku Salak The Snake Fruit.Penerbit Universitas Brawijaya Press (UB Press) malang

Raden Agus Bachtiar1, Sumarto1*, Deris Aprianty1 , Lusi Kristiana2, Maret 2018, Penyuluhan Gizi untuk Mengubah Pengetahuan dan Sikap Masyarakat terhadap Pengembangan Pangan Lokal Salak Manonjaya

Sugiyono. 2016. Metode Penelitian Kuantitatif, Kualitatif dan R \& D. Alfabeta. Bandung.

Supriyo Imran, Amelia Murtisari, Ni Ketut Murni,2014. Analisis Nilai Tambah Keripik Ubi Kayu di UKM Barokah Kabupaten Bone Bolango Jurnal Perspektif Pembiayaan dan Pembangunan Daerah Vol. 1 No. 4, April-Juni 2014 ISSN: 2338- 4603.

The FatSecret Platform API, Mei 2020 https://www.fatsecret.co.id/kalorigizi/umum/salak 